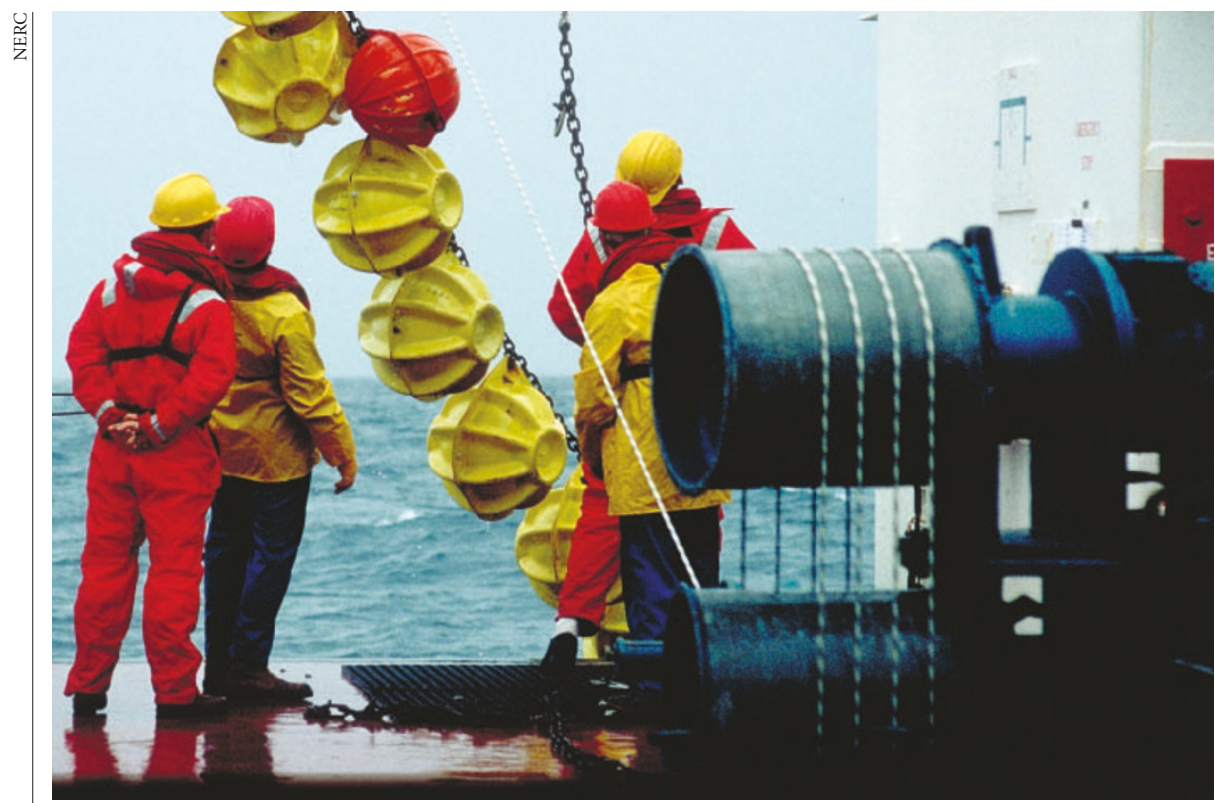

Sense of urgency: scientists on the Discovery deploy moorings that carry sensors to the ocean floor.

\title{
Gulf Stream probed for early warnings of system failure
}

Quirin Schiermeier, Munich

Climate researchers set sail from the Canary Islands today to begin an ambitious, fouryear programme that will assess the behaviour of currents, such as the Gulf Stream, in the north Atlantic Ocean.

The US\$20-million programme is part of a wider investigation into rapid climate change, known as Rapid. It will take the most detailed look yet at the strength, structure and variability of the currents that carry warmth northwards in the Atlantic.

Climatologists worry that global warming could disrupt these currents, which make Western Europe's climate far warmer than other parts of the world at the same latitude. Without the Gulf Stream, for example, the south of England would be as cold as Iceland.

Researchers think the currents are caused by a combination of wind, differences in water density, and the special geometry of Atlantic Ocean basins and the surrounding continents. They think the system may have broken down before, driving large, abrupt changes in climate (see Nature 364, 203-207; 1993).

Given the extent of global climate change at the moment, some suspect this could happen again. Models suggest that currents are already affected by increased freshwater flow from precipitation, river runoff and ice-sheet melting (see Nature 378, 145-149; 1995).

The Rapid team on board the British research vessel RRS Discovery will try to establish if this is really happening. "Complete collapse of the north Atlantic circulation is a worst-case scenario," says Stefan Rahmstorf, a climate modeller at the
Potsdam Institute of Climate Impact Research in Germany. "But no one really has any firm idea of what is going on out there, and that is why this project is so important."

The team will use 22 moorings across the subtropical Atlantic: near the Canary Islands, on the Mid-Atlantic Ridge and off the Bahamas. Sensors will travel up and down wires from buoys to the moorings on the sea floor. Differences in water density will be calculated from the temperature and salinity measured throughout these water columns. With US measurements from the Florida Strait and satellite observation of wind-driven surface currents, these will help researchers understand water flow in the north Atlantic.

"It is unlikely that we will detect dramatic changes within the next four years," says Jochem Marotzke, an oceanographer at the Max Planck Institute of Meteorology in Hamburg, and one of the principal investigators in Rapid. "But we will learn lots of exciting things about ocean circulation, and work out how to design a stable monitoring system for the next few decades." Rapid is being jointly sponsored by Britain's Natural Environment Research Council and the US National Science Foundation.

One long-term goal, says Marotzke, is an early-warning programme that would raise the alarm if the present system was close to failure. Even if nothing could be done, society could prepare for the results, he says. A German-Norwegian project called Integration is already assessing the impact of a failure on climate, fisheries and agriculture.

www.soc.soton.ac.uk/rapidmoc
Bioprospectors edge towards deal with developing countries

Rex Dalton, Kuala Lumpur

Guidelines for researchers, companies, governments and universities engaged in bioprospecting are to be drawn up within two years, representatives of nearly 200 nations have agreed.

Researchers hope the guidelines will help to calm global discord over the sharing of financial benefits from natural products, such as potential drug targets - particularly those found in poor nations that are rich in biodiversity.

After marathon negotiations at the Seventh Meeting of the Conference of the Parties to the Convention on Biological Diversity (CBD) in Kuala Lumpur, Malaysia, representatives agreed on 20 February for guidelines to be prepared in time for approval at the next conference in Rio de Janeiro, Brazil, in 2006.

The guidelines are set to incorporate the idea of an internationally recognized certificate of origin, as a kind of passport for any scientific discovery. This will allow the source country and developer to follow the trail from its place of origin to its commercial exploitation.

Some researchers have expressed concerns about the extra regulations. "It is a bitter pill to swallow. But the moral argument is uncontestable," says plant taxonomist Matthew Jebb, acting director of the National Botanic Gardens in Dublin, Ireland, who led the European Union's delegation in some of the talks. "We are reaping the legacy of more than 100 years of European domination."

The meeting rejected proposals from some poor countries for an extra treaty on access and benefit-sharing, as well as calls from rich nations for no extra rules.

Carlos Fernandez Ugalde, an environmental economist at Mexico's National Institute of Ecology and part of the Mexican delegation, says the outcome was satisfactory, but that it would be "a real challenge" to develop guidelines that would address the rights of indigenous people to traditional knowledge.

Delegates from Africa, Latin America and Asia complained about exploitation of genetic resources and failure to share the benefits. But drug companies say the CBD makes bioprospecting more trouble than it is worth in many countries.

The poorer countries also favour incorporating a discovery's place of origin into patent applications when the guidelines are implemented. But this is fiercely opposed by patent offices in rich countries such as the United States. 